Personality Neuroscience

cambridge.org/pen

\section{Empirical Paper}

Cite this article: De Pascalis V, Scacchia $P$, Papi B, and Corr PJ. (2019) Changes of EEG band oscillations to tonic cold pain and the behavioral inhibition and fight-flight-freeze systems. Personality Neuroscience. Vol 2: e12, 1-11. doi: 10.1017/pen.2019.9

Received: 4 November 2018

Revised: 21 August 2019

Accepted: 10 September 2019

\section{Key words:}

tonic cold-pain; electroencephalography (EEG); behavioral inhibition system;

fight-flight-freeze system

Author for correspondence:

Vilfredo De Pascalis,

Email: vilfredo.depascalis@uniroma1.it

\title{
Changes of EEG band oscillations to tonic cold pain and the behavioral inhibition and fight-flight-freeze systems
}

Vilfredo De Pascalis ${ }^{1}$ (1) , Paolo Scacchia ${ }^{1}$, Beatrice Papi ${ }^{1}$ and Philip J. Corr ${ }^{2}$

${ }^{1}$ Department of Psychology, La Sapienza University of Rome, Rome, Italy and ${ }^{2}$ Department of Psychology, City, University of London, London, UK (c) The Author(s) 2019. This is an Open Access article, distributed under the terms of the Creative Commons Attribution licence (http:// creativecommons.org/licenses/by/4.0/), which permits unrestricted re-use, distribution, and reproduction in any medium, provided the original work is properly cited.

\section{CAMBRIDGE} UNIVERSITY PRESS

\begin{abstract}
Using electroencephalography (EEG) power measures within conventional delta, theta, alpha, beta, and gamma bands, the aims of the current study were to highlight cortical correlates of subjective perception of cold pain (CP) and the associations of these measures with behavioral inhibition system (BIS), fight-flight-freeze system (FFFS), and behavioral approach system personality traits. EEG was recorded in 55 healthy right-handed women under (i) a white noise interruption detection condition (Baseline); (ii) enduring CP induced by the cold cup test. CP and Baseline EEG band power scores within conventional frequency bands served for covariance analyses. We found that: (1) higher Pain scorers had higher EEG beta power changes at left frontal, midline central, posterior temporal leads; (2) higher BIS was associated with greater EEG delta activity changes at parietal scalp regions; (3) higher FFFS was associated with higher EEG delta activity changes at temporal and left-parietal regions, and with lower EEG gamma activity changes at right parietal regions. High FFFS, compared to Low FFFS scorers, also showed a lower gamma power across the midline, posterior temporal, and parietal regions. Results suggest a functional role of higher EEG beta activity in the subjective perception of tonic pain. EEG delta activity underpins conflict resolution system responsible for passive avoidance control of pain, while higher EEG delta and lower EEG gamma activity changes, taken together, underpin active avoidance system responsible for pain escape behavior.
\end{abstract}

Experimental tonic pain in a non-clinical sample is a model that resembles clinical chronic pain and serves as a useful tool to examine underpinning brain mechanisms (Huber, Bartling, Pachur, Woikowsky-Biedau, \& Lautenbacher, 2006; Nir, Sinai, Moont, Harari, \& Yarnitsky, 2012). A plethora of electroencephalography (EEG) studies reported decreases of EEG alpha oscillations at around $10 \mathrm{~Hz}$ to tonic pain (Chang, Arendt-Nielsen, \& Chen, 2002a, 2002b; Chen \& Rappelsberger, 1994; Dowman, Rissacher, \& Schuckers, 2008; Nir et al., 2012; Peng, $\mathrm{Hu}$, Zhang, \& Hu, 2014; Shao, Shen, Yu, Wilder-Smith, \& Li, 2012), whereas other investigators obtained increases in the magnitude of gamma oscillations (30-100 Hz) (Dowman et al., 2008; Peng et al., 2014; Schulz et al., 2015; Veerasarn \& Stohler, 1992). However, little research effort has been devoted to study how individual differences in personality traits modulate EEG oscillations during tonic pain experience.

Among the neurophysiological-based personality theories that could potentially play an important role in pain experience is the revised reinforcement sensitivity theory (rRST) of personality (Corr, 2008; Corr \& McNaughton, 2012; Gray \& McNaughton, 2000; McNaughton \& Corr, 2008) that represents a reconceptualization of the RST originally formulated by Gray (1982, 1990). The behavioral inhibition system (BIS) and behavioral approach system (BAS) represent two neurophysiological brain systems that regulate how individuals respond to signals of potential punishment and/or reward. Specifically, the BIS is seen to be activated by signals of punishment and non-reward, novel stimuli, or unconditioned/conditioned fear stimuli. Its activation facilitates behavioral orienting through novel stimuli with interruption and inhibition of the ongoing behavior. The BAS is an appetitive-motivational system that is thought to respond to signals of reward and non-punishment. The BAS is activated by reward consumption and conditioned signals of reward or non-punishment and the associated approach behavior and positive emotions. In the rRST, the BAS is reconceptualized as a multidimensional system (Corr, 2016). The two systems work independently, although they can interact. While Gray's original conception of RST mentioned a less defined fight-flight system (FFS), rRST developed this system further into a fight-flight-freeze system (FFFS). The original conception of BIS dealt with responses to aversive stimuli, but in the rRST, the FFFS was primarily responsible for this role, while the BIS serves primarily to detect and resolve the conflict between BAS and FFFS. The FFFS encompasses functional behavioral responses to threat, including fighting the threat, fleeing in active avoidance, or freezing to avoid attracting the attention of the predator. Pain and other aversive treat stimuli can require either avoidance or cautious 
approach. Simple avoidance is thought to be controlled by the FFFS. A cautious approach, induced by approach-avoidance conflict, is thought to initiate a conflict resolution process in the BIS. This resolution process could increase behavioral inhibition, negative bias, arousal, attention, and risk assessment (McNaughton \& Corr, 2004).

Recent neuroimaging research has highlighted that BAS, but not BIS sensitivity of the Carver and White BIS/BAS scale (Carver \& White, 1994), is positively associated with $\mu$-opioid receptor availability in frontal cortex, cingulate cortex, insula amygdala, ventral, striatum, and brainstem, indicating that endogenous opioid system underlies BAS (Karjalainen et al., 2016). Although abovementioned studies indicate that pain responses may represent a form of responding to negative stimuli, the underlying brain mechanisms of the immediate effects of pain and their relation with motivational personality traits have been poorly understood. This is mainly due to the fact that, in motivational and physiological pain research, Carver and White BIS/BAS scale (Carver \& White, 1994) is the most extensively used personality questionnaire, which is limited to only two measures of BIS and BAS. In addition, the BAS scale has no clear theoretical justification for its subdivision in three components, that is, drive, reward responsiveness, and fun seeking (for review, see Harmon-Jones, Harmon-Jones, \& Price, 2013). However, the major problem with this questionnaire is the lack of separation of FFFS and BIS (Corr, 2016), which may account for inconsistent findings when relating BIS scale to placebo and nocebo effects (Corsi \& Colloca, 2017). For example, Peciña et al. (2013) found that neuroticism was a negative predictor, while ego-resilience and agreeableness were positive predictors of pain reduction magnitude. Coen et al. (2011) found no influence of neuroticism on pain perception, whereas they found a positive correlation between brain activity and neuroticism during pain anticipation in regions associated with emotional and cognitive pain processing, including the parahippocampus, insula, thalamus, and anterior cingulate cortex (ACC). In contrast, these regions showed a negative correlation with neuroticism during pain perception. Further, neuroticism was also negatively correlated to ventral ACC activity when shocks were expected (Kumari, Das, Wilson, Goswami, \& Sharma, 2007). Overall, BIS and FFFS-related personality traits were found positively correlated with ACC and posterior cingulate cortex (PCC) reactivity in response to negative events, and negatively with PCC activity while anticipating a negative event (for review, see Kennis, Rademaker, \& Geuze, 2013).

Consistent with theoretical and empirical considerations of the rRST, a new questionnaire has been proposed, namely the Reinforcement Sensitivity Theory of Personality Questionnaire (RST-PQ; Corr \& Cooper, 2016), developed on the basis of qualitative responses to defensive and approach scenarios. The RST-PQ highlighted a robust six-factor structure: two unitary defensive factors, the FFFS related to fear and the BIS related to anxiety, and four BAS facets (Reward Interest, RI; Goal-Drive Persistence, GDP, Reward Reactivity, RR; Impulsivity, Imp). The RST-PQ allows the separation of GDP, RI, and RR from Imp sub-factors of the BAS, making possible to test the unique predictive power of each subfactor. Reward theory distinguishes between the anticipation of reward, closely linked to the motivation to obtain the reward, and the actual hedonic experience of reward ("wanting" vs. "liking") (Berridge, 1996; Berridge, Robinson, \& Aldridge, 2009). Whereas the "liking" component is associated with striatal opioids (Peciña \& Berridge, 2000), "wanting" seems to be related to dopaminergic neurotransmission in the ventral striatum (Wyvell \& Berridge, 2000). Individuals differ with respect to their sensitivity to reward and reward-predicting cues (Beaver et al., 2006; Cohen, Young, Baek, Kessler, \& Ranganath, 2005; Shoaib, Spanagel, Stohr, \& Shippenberg, 1995) and, in particular, "wanting" personality traits as assertiveness and reward sensitivity (i.e., drive and interest to achieve a reward) are associated with dopaminergic neurotransmission (DeYoung, 2010; Yacubian et al., 2007). The magnitude of opioid as well as dopamine release in the ventral striatum is related to the amount of pain relief (Scott et al., 2007, 2008; Zubieta et al., 2005), while change in the actual enjoyment of reward once it is achieved ("liking") seems to be more closely related to opioidergic than to dopaminergic neurotransmission (Drago, Caccamo, Continella, \& Scapagnini, 1984; Schweinhardt, Seminowicz, Jaeger, Duncan, \& Bushnell, 2009; Shimizu et al., 2004). In this vein, since RI and GDP components of the BAS are conceptualized to serve the early stages of approach behavior (wanting or reward anticipation), these traits can be seen as the approach components linked to the dopaminergic activity. Additionally, as RR and Imp facets of the BAS are thought to serve the emotional excitement to reward, these traits are likely to depend from the function of the endogenous opioid system, which is mainly activated by the final biological reinforcer (Karjalainen et al., 2016; Peciña et al., 2013).

In the RST-PQ, the BIS and FFFS measures are postulated to have different functional properties and distinct neuropsychopharmacological bases (Corr \& McNaughton, 2012; McNaughton \& Corr, 2008) and separate sources of aversion (Perkins, Kemp, \& Corr, 2007). However, we do not currently have specific biological markers that can be used to distinguish these sources in humans. According to McNaughton and Corr (2008), these two dimensions account for the differentiation between different defensive behaviors and involve somewhat different neural networks, especially with active versus passive avoidance. Serotonergic and noradrenergic fibers that essentially mediate global threat sensitivity are seen to modulate all the structures controlling defense (for more details, see Corr, DeYoung, \& McNaughton, 2013).

EEG research on RST-related personality primarily attempted to link lateral frontal cortex, especially on the right, with avoidancerelated processing mainly using Carver and White (1994) BIS/ BAS scales to resting EEG alpha activity but inconsistent findings were found (for review, see Kennis, Rademaker, \& Geuze, 2013; Wacker, Chavanon, \& Stemmler, 2010). Original studies which related the BIS subscale with right frontal activity did not consider that Carver and White (1994) BIS scale was developed with only one general avoidance system in mind. However, research has linked right frontal activity to BIS-related states of response inhibition, and regulatory control. Enhanced activity in the right inferior frontal gyrus, following transcranial direct current stimulation, did produce greater response inhibition in a stop-signal task (Jacobson, Javitt, \& Lavidor, 2011; Stramaccia et al., 2015) and, conversely, lesions of the right prefrontal cortex led to poor inhibition in a stop-signal task (Aron, Fletcher, Bullmore, Sahakian, \& Robbins, 2003). Kelley and Schmeichel (2016) found the right frontal cortex involved in the inhibition of both approach and avoidance behavior, a key function of the BIS. Research using large samples of resting data has demonstrated greater BIS-anxiety related to the greater relative right frontal activity (De Pascalis, Fracasso, \& Corr, 2017; Neal \& Gable, 2016, 2017). Knyazev et al., using resting EEG data, also found that the relative prevalence of parietal alpha power and reduction in delta power were associated with higher BIS/N individuals, whereas relative prevalence of delta oscillations, mostly in the frontal region, predicted higher BAS impulsive individual (Knyazev, 2006; Knyazev \& Slobodskaya, 2003). Other authors reported a negative association between theta power and neuroticism (Chi et al., 2005). A large 
literature suggests that enhanced theta activity in response to emotional stimuli is an index of perceived motivational salience, that is, the significance of a stimulus to the individual (Güntekin \& Başar, 2014; Knyazev, 2007; Knyazev, Slobodskoj-Plusnin, \& Bocharov, 2009). Frontal theta is generated in the ACC, which is crucial in the evaluation of stimulus salience in order to drive behavior (Bush, Luu, \& Posner, 2000; Pizzagalli, Oakes, \& Davidson, 2003). Andersen, Moore, Venables and Corr (2009) found theta band power especially responsive to anxious ruminative thinking and consistent with the model of recursive processing between the hippocampus and neocortex during goal-conflict resolution proposed by Gray and McNaughton (2000). Higher theta power reactivity to response execution during goal conflict in higher BIS participants was later reported by Moore, Mills, Marshman and Corr (2012) in a continuous monitoring task. Right frontal theta power has been found to increase in both conflict- and loss-induced theta power and associated with higher neuroticism scores (Neo \& McNaughton, 2011). Very recently, we obtained heart-rate variability and conventional EEG band power measures during cold pain (CP) and placebo analgesia to identify RST-PQ traits that predict placebo analgesic responding. We found that a linear compound of HR slowing and higher EEG delta activity during placebo analgesia explained a substantial proportion of the variance in placebo analgesic responses, wherein RI had a significant mediating effect. These findings parallel our previous observations of reduced current density in the primary somatosensory cortex in higher total BAS and RI participants (De Pascalis \& Scacchia, 2017a, 2017b). Other studies have outlined delta oscillations as a correlate of basic homeostatic and motivational processes as those involved in the detection of motivationally salient stimuli of reward and defensive mechanisms associated with pain and anxiety (Knyazev, 2007, 2012; Knyazev et al., 2009) and behavioral inhibition (Harmony, 2013; Kamarajan et al., 2004; Knyazev, 2007; Putman, 2011).

To date, research using primarily Carver and White (1994) BIS scale has not identified a neurocognitive correlate of this trait in humans (Kennis et al., 2013; Wacker et al., 2010). Thus, on the basis of the abovementioned EEG-pain findings, the aims of the present study were to detect, among EEG delta, theta, alpha, beta, and gamma bands, the brain rhythm sensitive to tonic CP and to highlight those sensitive to individual differences in pain and distress sensations. A further aim was to evaluate the link of both BIS and FFFS, as measured by the RST-PQ, with pain and distress sensations and to identify EEG band regional rhythms that can differentiate the defensive systems in terms of the BIS and FFFS. In line with Gray and McNaughton (2000) view, during pain, we expected a positive link between EEG theta activity and BIS scores as well as between delta activity and BIS scores. Finally, assuming that higher FFFS scorers should be prone to avoid painful stimulation, or to pay less attention to painful stimulation, we expected a reduced activity within the high-frequency EEG bands in these individuals. Finally, considering that BAS trait and its facets are activated by reward, we did not expect a link between pain sensation or EEG activity and these personality measures.

\section{Methods}

\subsection{Participants}

A total of 60 right-handed women $(M=23.8, S D=2.1$ years, range 19-32 years) student volunteers participated in the study, 4 of them were excluded for large EEG artifacts and 1 for presenting outliers, leaving 55 participants available for data analyses. We tested our

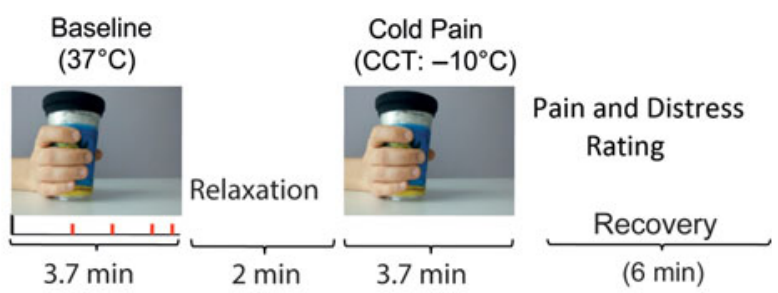

White Noise with $25 \mathrm{~ms}$

noise interruptions

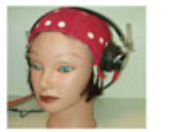

EEG Recordings

(eyes open)

Figure 1. Schematic diagram depicting experimental treatments and procedure. Left quadrant in the panel shows a Baseline condition during which participants had to detect interruptions of a continuous white noise (Baseline). Right quadrant in the panel shows enduring CP induced by the CCT. Treatments were administered in counterbalanced order across participants. Following CP treatment, participants rated the intensity of experienced pain and distress sensation.

hypotheses only in women since a body of literature clearly suggests that men and women differ in their responses to pain, with women being more sensitive (Bartley \& Fillingim, 2013; Berkley, 1997). Further, to avoid individual differences in pain sensitivity due to menstrual pain, participants who were in a menstrual period were invited for the EEG recordings between the 5th and 11th day after the onset of menses. The study was approved by the institutional review board of the Department of Psychology according to Helsinki Declaration. Participants signed approved informed consent forms.

\subsection{Questionnaires}

The handedness of participant was assessed using the Italian version of the Edinburgh Inventory Questionnaire (Oldfield, 1971). Participants also completed the RST-PQ (Corr \& Cooper, 2016). This tool measures three major systems: FFFS (related to fear); BIS (related to neuroticism/anxiety); BAS. The BAS, namely the total BAS, is a composite of four subscales Reward Reactivity (BAS-RR), Impulsivity (BAS-IMP), Goal-Drive Persistence (BASGDP), and BAS-Reward Interest (BAS-RI). Just before starting the EEG recordings, participants completed the State Anxiety Inventory (Spielberger, Gorsuch, Lushene, Vagg, \& Jacobs, 1988) to measure state anxiety.

\subsection{Experimental procedure}

Participants came to the laboratory and consented to participate. They first completed the handedness and personality questionnaires and, then, an electro cap for EEG recordings was fitted. Participants completed an averaged time of about 13 min of EEG recordings during two treatments with eyes open (see Figure 1).

CP was induced by administration of the cold cup test (CCT; Chen, Chang, \& Arendt-Nielsen, 2000; De Pascalis \& Scacchia, 2019). The CCT can be considered as a variation of the ice-water cold-pressor test. This CCT proved to be convenient and consistent across the testing conditions. Participants received two treatments of 3.7 min each: (i) no-pain active Baseline, requiring to hold, in the right hand, a cup at about $37^{\circ} \mathrm{C}$ while listening, via binaural headphone, a continuous broadband white noise $(70 \mathrm{~dB}, 0-44 \mathrm{kHz})$ 
wherein there were eight short interruptions $(25 \mathrm{~ms}$, rise time $=5 \mathrm{~ms}$ ), randomly distributed within the Baseline time; and (ii) CCT, requiring a natural holding in the right hand of a tin-plastic chilled cold cup at $-10^{\circ} \mathrm{C}$. During the Baseline condition, the participant was required to pay attention to the ongoing white noise and to count the number of any possible changes in sound interruption, if any. As soon as the Baseline period was over, participants had to report verbally the number of white noise interruptions they detected. This Baseline condition was attempted to minimize the variability in arousal, attention, and vigilance both between and within participants by the auditory task. According to previous research (Dowman et al., 2008; Shao et al., 2012), the active non-pain condition should represent a better Baseline condition in contrast to the $\mathrm{CP}$ condition than the classic passive no-task control condition. Just at the end of CP treatment, the participant was required to rate the perceived pain and distress scores (NPS and NDS) on two separate 11-point (0-100) numerical rating scales (NRSs) (Jensen, Karoly, \& Braver, 1986). The NRS for the perceived pain intensity was as follows: $0=$ no pain, $10=$ barely noticeable pain, $50=$ mild pain, and $100=$ maximum pain tolerable. The NRS for the perceived pain distress was as follows: $0=$ neutral, $1=$ barely distressing, $5=$ distressing, and $10=$ worst distressing imaginable. $\mathrm{CP}$ and Baseline treatments were administered in counterbalanced order across participants. In the cases in which Baseline preceded CP treatment, a 2-min relaxation period was given between treatments, in the opposite cases, the relaxation period was of $6 \mathrm{~min}$.

\subsection{EEG recording and processing}

Participants were seated in a semi-reclined position inside a quiet dimly lit room. They were fitted with a pure-tin electrode electrocap (Electro-Caps, Eaton, OH, USA) using an electrode placement based on the 10-20 system with a ground electrode mounted between $\mathrm{FPz}$ and $\mathrm{Fz}$. Scalp EEG was recorded from 30 scalp sites (Fp1, Fp2, F7, F8, F3, F4, FT7, FT8, T3, T4, FC3, FC4, C3, C4, CP3, CP4, TP7, TP8, T5, T6, P3, P4, O1, O2, Fz, FCz, Cz, CPz, Pz, Oz) and referenced online to digitally linked ears $[(\mathrm{A} 1+\mathrm{A} 2) / 2]$.

Bipolar horizontal and vertical electrooculograms (EOG) were recorded respectively from the epicanthus of each right and left eye, and from supra- and infra-orbital positions of the right eye using standard tin electrodes. Electrode impedances were kept under $5 \mathrm{k} \Omega$, with homologous sites kept within $1 \mathrm{k} \Omega$ of one another. Data were collected using a 40-channels Neuroscan NuAmp amplifier unit (El Paso, TX, USA) settled in DC mode with a gain of 200 (100 for eye channels) and a band-pass of $0.01-75 \mathrm{~Hz}$ (Butterworth zero phase filter with $24 \mathrm{~dB}$ /octave roll off), notch filtered at $50 \mathrm{~Hz}$ (range $5 \mathrm{~Hz}$ ), and digitized at $1000 \mathrm{~Hz}$. EEG time series were then re-referenced to a common average reference and segmented into consecutive 2 -s intervals. In order to eliminate artifacts, all data were offline visually inspected and handcorrected for eyeblink artifacts using Brain Vision Analyzer 2.1 software. Eye-movement artifacts were removed by extracting 1-3 out of 30 independent components (IC; using Infomax algorithm, Brain Products; Vision Analyzer 2.01, Gilching, Germany) that clearly represented vertical and horizontal eye movements and had been identified by visual (topographic) inspection of the independent component analysis (ICA) maps and comparisons with the EEG and EOG time series (Delorme, Sejnowski, \& Makeig, 2007; Olbrich, Jödicke, Sander, Himmerich, \& Hegerl, 2011). Due to the influence of ICA correction on coherence measures (Castellanos \& Makarov, 2006; Olbrich et al., 2011), only ICs without visible neural activity were discarded. Any segment that still contained muscle, movement, sweating, or eye-movement artifacts, as revealed by a visual inspection by two experienced clinical raters, was excluded from further analysis (no subject had more than $15 \%$ artifacts). A frequency resolution of $0.5-\mathrm{Hz}$ steps for assessment of the different EEG bands was obtained. These 2-s EEG epochs were exported for further analysis.

\subsection{EEG quantification}

The data were parsed into 2-s epochs through a Hamming window, which was specified to diminish the signal on $10 \%$ at the borders of the epoch, to prevent spurious estimates of spectral power. After a visual re-examination for muscle, eye, movement, sweat, and technical artifacts, artifact-free epoch data were identified and, to facilitate later processing, downsampled to $256 \mathrm{~Hz}$. An average of 90.7 $(S D=5.8)$ and $88.2(S D=7.1)$ of usable non-overlapping epochs were obtained, respectively, for Baseline and Pain conditions in each participant. Fast Fourier transform algorithm was used to perform EEG frequency analysis, with 2-s interval on the EEG signal, in all scalp locations. The bands inspected were the traditional delta $(0.5-$ $3.75 \mathrm{~Hz})$, theta $(4-7.75 \mathrm{~Hz})$, alpha $(8-12.75 \mathrm{~Hz})$, beta $(13-35.75 \mathrm{~Hz})$, and gamma $(36-45 \mathrm{~Hz})$, and power values were averaged across epochs. Since the CP has a strong negative valence, which is known to increase over the course of time (Streff, Kuehl, Michaux, \& Anton, 2010), power spectra were computed $30 \mathrm{~s}$ after that painful stimulation had started. The same starting time of $30 \mathrm{~s}$ was used for EEG analysis during the Baseline. Power values were natural-logarithm (ln) transformed to normalize the data (Gasser, Bächer, \& Möcks, 1982). These values were then used to calculate EEG band power changes from Baseline by subtracting EEG band values during Baseline from those obtained during Pain. Based on previous pain study reports (Apkarian, Bushnell, Treede, \& Zubieta, 2005; Dowman et al., 2008; Koessler et al., 2009; Okamoto et al., 2004), we selected for statistical analyses the following 15 scalp recording sites: F7, F3, Fz, F4, F8, T3, C3, Cz, C4, T4, T5, P3, Pz, P4, and T6.

\subsection{Statistical analyses}

To evaluate the relation of pain with personality measures of interest, we first calculated the zero-order correlation of NPS, NDS, state anxiety, and RST-PQ traits. Significance of these correlations was assessed using the bias-corrected bootstrap method, which is effective in controlling for type 1 errors associated with multiple comparisons (Efron \& Efron, 1982; Efron \& Gong, 1983). For each correlation, we also computed the $95 \%$ confidence intervals (CI) using bootstrap resampling (5000 samples, biascorrected confidence limits). All significant coefficients with an associated CI that did not include zero were considered statistically significant $(P<.05)$.

To evaluate the effect of pain and personality on EEG activity, separate ANCOVAs were applied (SAS-9.4 system) using each of the associated pain and personality measures as a covariate. Condition (Baseline, CP) and Topography served as within subject's factors. Within Topography, sagittal plane (anterior-frontal [F7, F3, Fz, F4, F8], temporo-central [T3, C3, Cz, C4, T4] and temporo-parietal $[\mathrm{T} 5, \mathrm{P} 3, \mathrm{Pz}, \mathrm{P} 4, \mathrm{~T} 6]$ regions) and coronal plane (left-1 [F7, T3, T5], left-2 [F3, C3, P3], midline [Fz, Cz, Pz], right-1 $[\mathrm{F} 4, \mathrm{C} 4, \mathrm{P} 4]$, right-2 [F8, T4, T6] regions) were repeated-measures factors. An $\alpha$ level of .05 was used for all analyses. Huynh-Feldt adjustments were used when the assumption of sphericity was violated. To control for false-positive errors, significance levels were corrected using the false discovery rate (FDR) method ("proc multitest," SAS-9.4; Benjamini \& Hochberg, 1995). Only for 


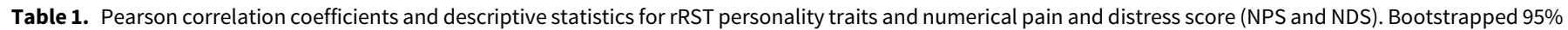
$\mathrm{Cl}$ is reported in parentheses $(N=55)$

\begin{tabular}{|c|c|c|c|c|c|c|c|c|c|}
\hline Variable & 1 & 2 & 3 & 4 & 5 & 6 & 7 & 8 & 9 \\
\hline 1. BIS & 1 & & & & & & & & \\
\hline 2. FFFS & $\begin{array}{c}\mathbf{0 . 4 7}^{\star \star \star} \\
(0.36,0.59)\end{array}$ & 1 & & & & & & & \\
\hline 3. BAS-RR & $\begin{array}{c}-0.16 \\
(-0.37,0.01)\end{array}$ & $\begin{array}{c}0.11 \\
(-0.19,0.13)\end{array}$ & 1 & & & & & & \\
\hline 4. BAS-IMP & $\begin{array}{c}-0.13 \\
(-0.21,0.12)\end{array}$ & $\begin{array}{c}-0.17 \\
(-0.35,0.08)\end{array}$ & $\begin{array}{c}\mathbf{0 . 4 6}^{\star \star \star} \\
(0.30,0.65)\end{array}$ & 1 & & & & & \\
\hline 5. BAS-GDP & $\begin{array}{c}0.11 \\
(-0.03,0.24)\end{array}$ & $\begin{array}{c}-0.01 \\
(-0.17,0.23)\end{array}$ & $\begin{array}{r}\mathbf{0 . 3 7 ^ { \star \star }} \\
(0.31,0.52)\end{array}$ & $\begin{array}{c}0.12 \\
(-0.06,0.13)\end{array}$ & 1 & & & & \\
\hline 6. BAS-RI & $\begin{array}{c}-\mathbf{0 . 3 7 ^ { \star \star }} \\
(-0.53,-0.19)\end{array}$ & $\begin{array}{c}-0.14 \\
(-0.19,0.21)\end{array}$ & $\begin{array}{c}\mathbf{0 . 4 7 ^ { \star \star }} \\
(0.35,0.57)\end{array}$ & $\begin{array}{c}\mathbf{0 . 5 1 \dagger} \\
(0.35,0.68)\end{array}$ & $\begin{array}{c}\mathbf{0 . 5 2} \dagger \\
(0.32,0.65)\end{array}$ & 1 & & & \\
\hline 7. NPS & $\begin{array}{c}0.00 \\
(-0.13,0.18)\end{array}$ & $\begin{array}{c}-0.00 \\
(-0.15,0.22)\end{array}$ & $\begin{array}{c}0.09 \\
(-0.03,0.21)\end{array}$ & $\begin{array}{c}0.24 \\
(-0.00,0.28)\end{array}$ & $\begin{array}{c}0.05 \\
(-0.09,0.28)\end{array}$ & $\begin{array}{c}0.06 \\
(-0.12,0.21)\end{array}$ & 1 & & \\
\hline 8. NDS & $\begin{array}{c}0.07 \\
(0.15,0.26)\end{array}$ & $\begin{array}{c}0.06 \\
(-0.06,0.25)\end{array}$ & $\begin{array}{c}0.21 \\
(0.09,0.31)\end{array}$ & $\begin{array}{c}0.24 \\
(0.12,0.35)\end{array}$ & $\begin{array}{c}0.06 \\
(-0.07,0.26)\end{array}$ & $\begin{array}{c}0.17 \\
(-0.14,0.23)\end{array}$ & $\begin{array}{c}\mathbf{0 . 6 6}^{\dagger} \\
(0.55,0.80)\end{array}$ & 1 & \\
\hline 9. STAI-Y1 & $\begin{array}{r}\mathbf{0 . 4 2} \mathbf{2}^{\star \star} \\
(0.35,0.57)\end{array}$ & $\begin{array}{c}0.24 \\
(0.00,0.26)\end{array}$ & $\begin{array}{c}-\mathbf{0 . 3 3}^{\star} \\
(-0.43,-0.20)\end{array}$ & $\begin{array}{c}-\mathbf{0 . 3 1 ^ { \star }} \\
(-0.39,-0.18)\end{array}$ & $\begin{array}{c}-0.20 \\
(-0.26,-0.01)\end{array}$ & $\begin{array}{c}-\mathbf{0 . 2 8}^{\star} \\
(-0.35,-0.11)\end{array}$ & $\begin{array}{c}-0.10 \\
(-0.12,0.15)\end{array}$ & $\begin{array}{c}-0.01 \\
(-0.11,0.21)\end{array}$ & 1 \\
\hline Mean & 52.1 & 26.5 & 29.8 & 17.5 & 23.1 & 19.7 & 55.4 & 36.8 & 34.9 \\
\hline$S D$ & 9.3 & 5.3 & 3.8 & 3.9 & 3.9 & 3.5 & 21.9 & 26.5 & 5.9 \\
\hline Range & $32-79$ & $17-40$ & $24-39$ & $10-29$ & $10-30$ & $11-28$ & 17-93 & $0-94$ & $21-47$ \\
\hline Cronbach's $\alpha$ & .89 & .81 & .79 & .76 & .83 & .78 & - & - & .82 \\
\hline
\end{tabular}

BIS, behavioral inhibition system; FFFS, fight-flight-freeze system; T-BAS, total score for behavioral approach system; GDP, goal-drive persistence; RI: reward reactivity; Imp: impulsivity. Notes: Personality Measures: Reinforcement Sensitivity Theory Personality Questionnaire (RST-PQ; Corr \& Cooper, 2016).

NPS and NDS: 0-100 Numeric Rating Scale (Jensen, Karoly, \& Braver, 1986). STAI-Y1: State Anxiety (Spielberger et al., 1988).

${ }^{\star} P<.05 ;{ }^{\star \star} P<.01 ;{ }^{\star \star \star} P<.001 ;{ }^{\dagger} P<.0001$.

Bold entries indicate significant values.

graphical illustrations, and to understand the direction of changes of significant main and/or interaction effects involving NPS or personality traits of interest, we applied separate median splits on these self-report measures. Participants were considered as belonging to either group "high" (Hi) or "low" (Lo) when their scores on the pain and personality measures were above or below the median. Pain and personality scores falling on the median were excluded.

\section{Results}

\subsection{Correlations among RST-PQ personality traits and NPS and NDS measures}

Pearson correlation coefficients (bias-corrected bootstrap method) among RST-PQ personality traits, state-anxiety, NPS, and NDS ratings together with descriptive statistics are reported in Table 1. Correlations among personality measures confirm the pattern of originally reported associations (Corr \& Cooper, 2016), while no significant correlations were found between RST-PQ traits as well as state anxiety and pain sensation measures.

\subsection{Pain perception, BIS, FFFS, and relevant EEG band power measures}

For each of the EEG delta, theta, alpha, beta, and gamma band power measures, separate ANCOVAs were performed by separately using each of the self-reported measures of interest as a covariate (i.e., pain and distress ratings and RST-PQ traits). Results of the ANCOVAs are given in Table 2. Additionally, for graphical illustrations, and to display the direction of significant changes, post-hoc $t$-tests were performed based on a median split of NPS, BIS, and FFFS scores (see Figures 2-5). The number of individuals falling on the median was: 7 for NPS $(N=26$ Hi-NPSs and $N=22$ Lo-NPSs); 5 for BIS (27 Hi-BIS, 23 Lo-BIS); and 6 for FFFS (24 Hi-FFFS, 25 Lo-FFFS).

\subsection{Pain perception and EEG beta band power}

Using NPSs as a covariate, we obtained, for beta band power, a significant Coronal by Sagittal by NPS interaction, revealing a significantly higher beta power in Hi-Pain than Lo-Pain scorers at frontal and right-parietal leads (see Table 2 and Figure 2(a)). In addition, for beta power, the Coronal by Sagittal by NPS by Condition interaction was also significant. This interaction disclosed a significantly higher beta power in High-Pain scorers at Fz, FCz, Cz, F8, $\mathrm{T} 5$, and T6 leads during $\mathrm{CP}$ and at F3, F4, FC4, and P4 leads during Baseline (Table 2 and Figure 2(b)). No significant effects involving distress rating scores were observed for the EEG band power measures of interest.

\subsection{Effects of BIS and FFFS on EEG delta and gamma powers}

No significant effects involving any of RST-PQ traits were obtained for theta and alpha band power measures.

The ANCOVA performed on delta power scores, using BIS as a covariate, disclosed a significant effect for Coronal plane followed by a significant four-way interaction for Coronal by Sagittal by BIS by Condition. These effects revealed that during CP condition 


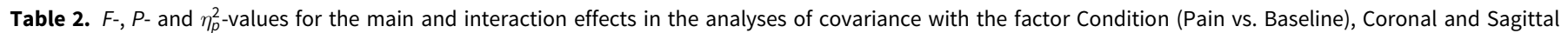
topography in the $2 \times 3 \times 5$ factorial design for EEG band power measures

\begin{tabular}{|c|c|c|c|c|c|c|c|c|c|c|c|c|}
\hline \multirow{2}{*}{$\begin{array}{l}\text { ANCOVA } \\
2 \text { Condition } \times 3 \text { Sagittal } \times 5 \text { Coronal } \times \text { Covariate }\end{array}$} & \multicolumn{3}{|c|}{ Beta: covariate $=$ NPS } & \multicolumn{3}{|c|}{ Delta: covariate $=$ FFFS } & \multicolumn{3}{|c|}{ Delta: covariate $=$ BIS } & \multicolumn{3}{|c|}{$\begin{array}{c}\text { Gamma: } \\
\text { covariate }=\text { FFFS }\end{array}$} \\
\hline & $F$ & $P$ & $\eta_{p}^{2}$ & $F$ & $P$ & $\eta_{p}^{2}$ & $F$ & $P$ & $\eta_{p}^{2}$ & $F$ & $P$ & $\eta_{p}^{2}$ \\
\hline Covariate & 4.05 & .080 & 0.684 & 0.13 & .850 & 0.002 & 6.15 & .048 & 0.110 & 1.46 & .5379 & 0.026 \\
\hline Condition & 1.99 & .194 & 0.031 & 1.48 & .521 & 0.020 & 0.17 & .811 & 0.003 & 1.08 & 538 & 0.019 \\
\hline Condition $\times$ Covariate & 2.12 & .194 & 0.031 & 1.00 & .521 & 0.020 & 0.02 & .881 & 0.000 & 1.11 & .538 & 0.021 \\
\hline Coronal plane & 0.38 & .699 & 0.007 & 19.75 & .0001 & 0.390 & 33.70 & .0001 & 0.890 & 3.28 & .1343 & 0.058 \\
\hline Coronal plane $\times$ Covariate & 1.81 & .194 & 0.021 & 1.23 & .521 & 0.023 & 3.79 & .059 & 0.071 & 2.23 & .2633 & 0.029 \\
\hline Coronal Plane $\times$ Condition $\times$ Covariate & 1.19 & .343 & 0.022 & 1.23 & .521 & 0.023 & 2.87 & .093 & 0.051 & 10.40 & .0001 & 0.164 \\
\hline Sagittal plane & 8.45 & .013 & 0.116 & 0.20 & .850 & 0.004 & 0.70 & .560 & 0.013 & 7.02 & .013 & 0.117 \\
\hline Sagittal plane $\times$ Covariate & 3.70 & .078 & 0.080 & 0.01 & .947 & 0.0002 & 0.12 & .844 & 0.002 & 1.46 & .549 & 0.021 \\
\hline Coronal $\times$ Sagittal & 4.81 & .031 & 0.075 & 1.97 & .947 & 0.037 & 2.46 & .093 & 0.046 & 0.75 & .758 & 0.014 \\
\hline Sagittal $\times$ Condition $\times$ Covariate & 5.69 & .030 & 0.110 & 0.94 & .521 & 0.018 & 2.33 & .188 & 0.043 & 1.12 & .538 & 0.019 \\
\hline Coronal $\times$ Sagittal $\times$ Condition & 4.73 & .0001 & 0.143 & 1.97 & .394 & 0.037 & 1.91 & .188 & 0.034 & 0.69 & .7583 & 0.012 \\
\hline Coronal $\times$ Sagittal $\times$ Covariate & 2.69 & .043 & 0.034 & 1.30 & .521 & 0.022 & 1.95 & .176 & 0.037 & 0.50 & .858 & 0.008 \\
\hline Coronal $\times$ Sagittal $\times$ Covariate $\times$ Condition & 3.04 & .031 & 0.094 & 3.31 & .007 & 0.090 & 2.44 & .049 & 0.041 & 0.74 & .7583 & 0.014 \\
\hline
\end{tabular}

$P$ values are corrected using FDR method. Bold entries indicate significant values.

Figure 2. Topographic patterns of significant ANCOVA effects (individual pain score (NPS) as a covariate) on beta power for (a) High-Pain vs. Low-Pain scorers; (b) Interaction of NPS with Topography and Condition (Baseline, CP). Independent $t$-test topographies compared High-Pain vs. Low-Pain scorers.

Pain: Beta 13-35.75 Hz

(a)

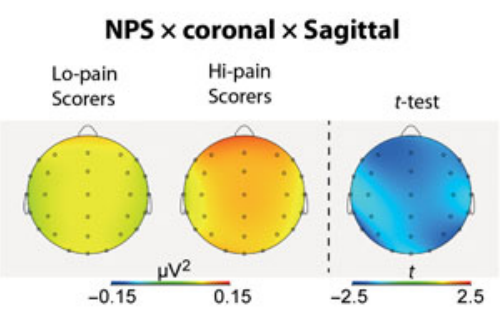

(b)

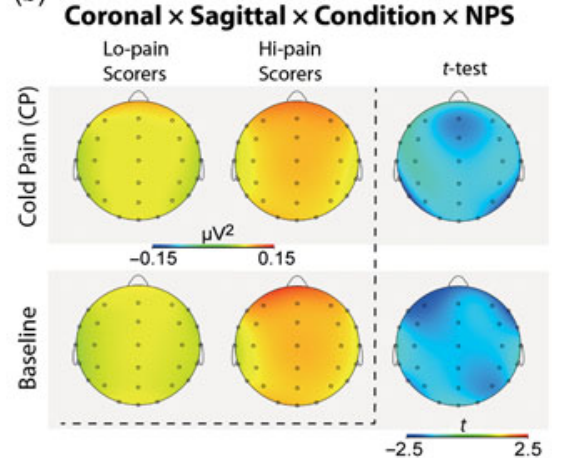

there was a higher delta power in Hi-BIS as compared to the Lo-BIS participants at $\mathrm{P} 3, \mathrm{Pz}$, and $\mathrm{P} 4$ leads (Table 2 and Figure 3).

A similar analysis conducted on delta power scores, using FFFS trait as a covariate, yielded a main effect for this trait, indicating that Hi-FFFS participants had a higher delta power than LoFFFS ones (Table 2 and Figure 4(a)). Moreover, the two-way Coronal by FFFS was near the significance level (FDR corrected $P=.059$ ), and four-way Coronal by Sagittal by Condition by FFFS interactions were all significant (Table 2). These effects indicated that Hi-FFFS scorers, for the $\mathrm{CP}$ condition, had a relatively greater delta power than Lo-FFFS scorers at T3, T5, P3, T4, and T6 leads, while for the Baseline these differences disappeared (Figure 4(b)).

Finally, ANCOVA on EEG gamma power disclosed significant effects for both Sagittal and Coronal planes and a significant threeway Coronal by Condition by FFFS interaction (Table 2). This interaction indicated that, during the $\mathrm{CP}$ condition, Hi-FFFS participants had a lower gamma power than Lo-FFFS ones across all midline sites (Fz, Cz, Pz) and left and right posterior temporal (T5, T6) and parietal leads (P3, P4) (Figure 5).

\section{Discussion}

Findings from the present study did not disclose significant EEG band oscillation changes between $\mathrm{CP}$ and Baseline condition. This means that our results did not support findings from previous studies in which cold-pressor test led to an increase in delta (Chen, Dworkin, Haug, \& Gehrig, 1989; Ferracuti, Seri, Mattia, \& Cruccu, 1994; Huber et al., 2006), theta (Chen, Rappelsberger, \& Filz, 1998; Russ, Campbell, Kakuma, Harrison, \& Zanine, 1999), beta, and gamma activity (Chang et al., 2002b; Shao et al., 2012). These differences could be due to the fact that we used an active Baseline task during which participants had to focus attention on task-relevant stimuli (i.e., they had to detect and count changes in the ongoing white noise) which may have produced a general activation response in this experimental condition 


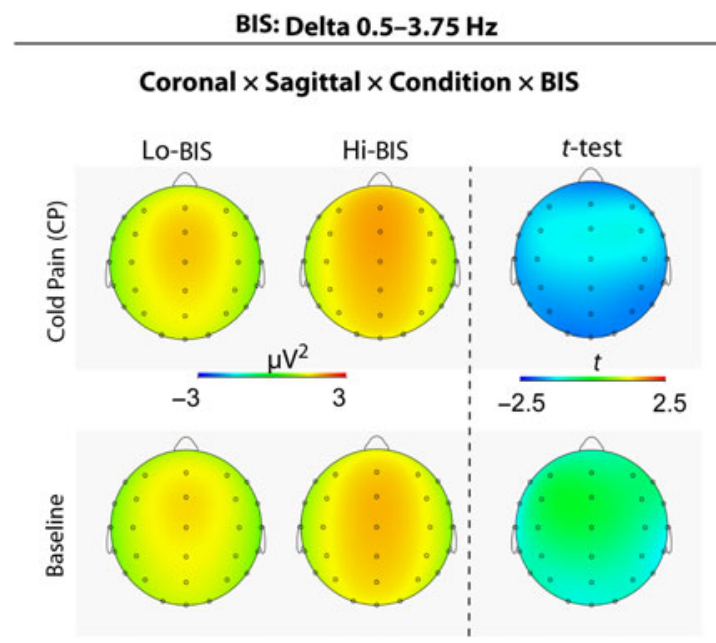

Figure 3. Delta power topographic patterns of a significant ANCOVA interaction of BIS trait (covariate) with Topography (Sagittal, Coronal plane) and Condition (Baseline, CP). Independent $t$-test topographies compared Low BIS vs. High BIS scorers.

(Peng et al., 2014). However, in the current study, ANCOVA analyses on the conventional EEG band oscillation changes, induced by CP from Baseline, disclosed that (a) beta power change was sensitive to individual differences in pain perception, (b) delta power to individual differences in BIS levels, and both delta and gamma powers to individual differences in FFFS traits.

In terms of pain perception (NPS), the ANCOVA performed on EEG beta band power scores disclosed a main effect for the covariate NPSs, indicating higher frontal beta activity in High-Pain scorers compared to Low-Pain scorers. This analysis also showed that these individual differences were more pronounced at $\mathrm{Fz}, \mathrm{Cz}$, F8, T5, and T6 leads during CP condition and at F3, F4, and P4 leads during Baseline condition (Table 2 and Figure 2). In the whole, these findings suggest a functional role of EEG beta activity in representing subjective experiences of tonic pain. Specifically, our finding of enhanced beta activity in pain-sensitive individuals (Table 2) is in line with those reported in previous studies using long-lasting tonic pain stimulations wherein tonic pain was found associated with decreased alpha and increased beta activities (Chang et al., 2002a; Chang, Arendt-Nielsen, Graven-Nielsen, Svensson, \& Chen, 2004; Chen \& Rappelsberger, 1994; Giehl, Meyer-Brandis, Kunz, \& Lautenbacher, 2014; Shao et al., 2012) and with higher beta power density findings (Huber et al., 2006; Ploner, Sorg, \& Gross, 2017). Research has also demonstrated that beta and gamma band activities enhance with heightened attention to pain stimulus (Hauck, Lorenz, \& Engel, 2007; Tiemann, Schulz, Gross, \& Ploner, 2010), vary with conscious perception (Gross, Schnitzler, Timmermann, \& Ploner, 2007) and attention effects of pain (Tiemann et al., 2010). Accordingly, our observations of enhanced relative fronto-temporal EEG beta activity to $\mathrm{CP}$ in Hi-Pain scorers may reflect the operation of an excitatory process employed for the encoding of subjective experiences of tonic pain. In contrast, the reduced beta activity in Lo-Pain scorers may reflect the disposition, in these individuals, toward an inhibitory attentional-shift from painful stimulus making a reduced pain perception. Moreover, the present data indicate that these EEG changes are specific to tonic $\mathrm{CP}$, as compared to changes observed during a non-painful Baseline stimulation, this is since we did not find any significant association between NPSs and state anxiety or dispositional personality traits of interest.
In terms of individual differences in rRST traits, our statistical analyses disclosed that Hi-BIS, as compared to Lo-BIS participants, had a relatively higher EEG delta power increase during CP across frontal, temporal, and parietal leads (Table 2 and Figure 3). These relatively new findings appear in line with few reports suggesting delta responses as a modulator of signal detection and decision making (Başar, Başar-Eroglu, Karakaş, \& Schürmann, 2001; Schürmann, Başar-Eroglu, Kolev, \& Başar, 2001), with studies indicating a role of delta oscillations in the synchronization of brain activity with autonomic functions in higher emotional involvement such as pain and in anxiety disorders (Knyazev, 2012). Delta activity was also associated with the detection of motivationally salient stimuli of reward and ancestral defensive mechanisms (Knyazev, 2007; Knyazev et al., 2009) and to behavioral inhibition (Harmony, 2013; Kamarajan et al., 2004; Knyazev, 2007; Putman, 2011). More specifically, Kamarajan et al. (2004) reported suppressions of frontal delta and theta responses in alcoholic individuals which are likely to show deficits in cognitive functions that are mediated by these oscillatory processes. Thus, the higher relative delta power, we obtained during CP, in Hi-BIS participants, may reflect the enhanced adaptive attempt devoted by these individuals to resolve the conflict associated with tonic pain perception (Amodio, Master, Yee, \& Taylor, 2008; De Pascalis, Varriale, \& D'Antuono, 2010), vice versa, the relative lower delta power we did find in Lo-BIS participants may reflect the reduced tendency to process tonic CP stimulation in these individuals. However, this interpretation remains a purely speculative attempt to explain current results considering that we have not found any significant association between NPS and BIS, FFFS, or BAS traits. It should be noted that a lack of association between pain perception and anxiety-related traits is not new. For example, in a previous personality-pain study (Coen et al., 2011) no association between neuroticism and pain ratings has been reported during visceral pain perception, although a negative correlation between neuroticism and brain activity was obtained in regions associated with emotional and cognitive pain processing, including the parahippocampus, insula, thalamus, and ACC (Coen et al., 2011). Additionally, in a previous fMRI-pain study (Kumari, Das, Wilson, Goswami, \& Sharma, 2007) neuroticism correlated positively with the ratings of fear of a shock and negatively with brain activity in the anterior and posterior cingulate, superior/middle temporal gyrus extending to the hippocampus, precuneus, putamen, thalamus, and middle occipital gyrus. These observations support the view of reduced processing of pain in subjects with higher levels of neuroticism, especially the anxiety component of this trait (Kumari et al., 2007). Further, fMRI findings (Bishop, Duncan, Brett, \& Lawrence, 2004) found that higher state anxiety levels were associated with both less rostral ACC activity and reduced recruitment of lateral $\mathrm{PFC}$, suggesting that higher state anxiety is associated with reduced top-down control over threatrelated stimuli. Unfortunately, we failed to extend abovementioned findings to tonic CP stimulation since we did not find a significant association between state anxiety and EEG power changes within conventional frequency bands during $\mathrm{CP}$. We also failed to find a significant association between midfrontal theta activity and BIS as reported in previous studies (Andersen et al., 2009; Cavanagh \& Shackman, 2015; Gray \& McNaughton, 2000; Moore et al., 2012; Neo \& McNaughton, 2011). This may depend from differences in the type of task used between the current and previous studies. For example, while in previous studies the BIS-theta relationship was found for designed tasks requiring rapid resolution of a cognitive goal conflict (e.g., Moore, Gale, Morris, \& Forrester, 
FFFS: Delta 0.5-3.75 Hz

(a)

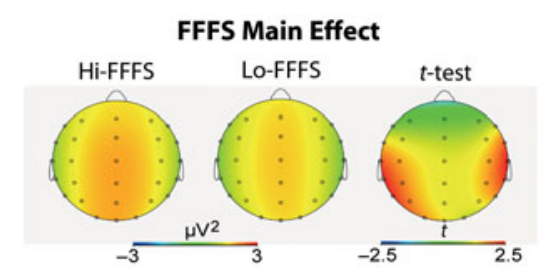

(b) Coronal $\times$ Sagittal $\times$ Condition $\times$ FFFS

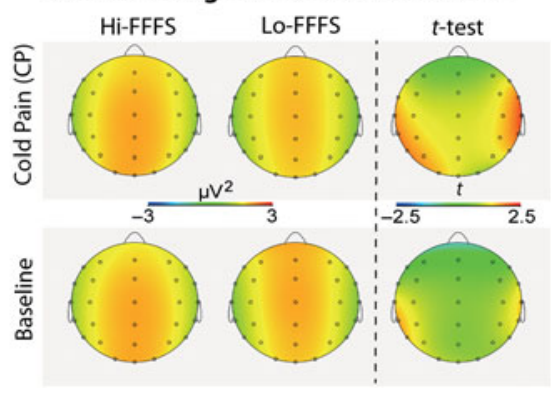

Figure 4. Topographic patterns of significant ANCOVA effects on delta power for (a) High FFFS vs. Low FFFS scorers; (b) Interaction of FFFS with Topography and Condition (Baseline, CP). Independent $t$-test topographies compared High FFFS vs. Low FFFS scorers. a) (b)
FFFS: Gamma 36-45 Hz

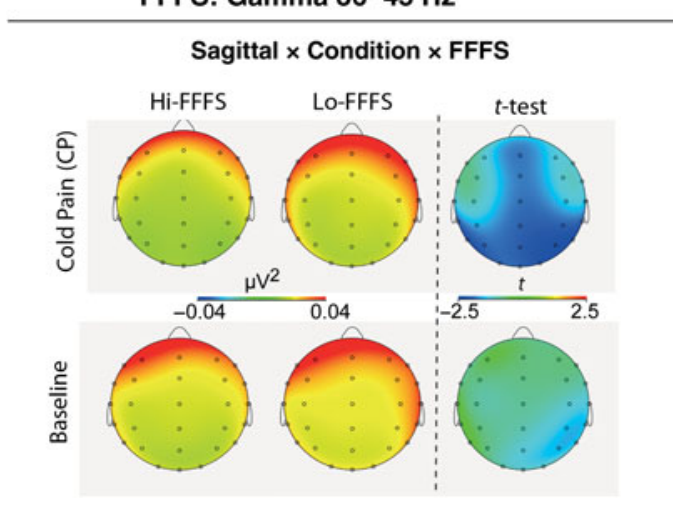

Figure 5. Gamma power topographic patterns of a significant ANCOVA interaction of FFFS trait (covariate) with Topography (Sagittal, Coronal plane) and Condition (Baseline, CP). Independent $t$-test topographies compared High FFFS vs. Low FFFS scorers.

2006; Moore et al., 2012; Neo \& McNaughton, 2011), in the current study the conflict consisted in paying attention to a continuous white noise in order to rate it. Thus, further investigation is justified.

In terms of the FFFS trait, ANCOVA analysis disclosed that HiFFFS participants, compared to Lo-FFFS participants, had higher delta power changes to $\mathrm{CP}$ at right-temporal and left-parietal leads, whereas they had lower gamma power changes at midline frontocentral and right parietal leads (Table 2; Figures 4 and 5). It is important to note that in the present study painful stimulation cannot be avoided, and the main function of FFFS activation serves to actively avoid the treat (active avoidance; Corr \& McNaughton, 2012). Considering that in previous studies delta activity was found associated with functional cortical deafferentation of sensory inputs that interfere with internal concentration necessary to accomplish a given task (Buzsáki, 2006; Harmony, 2013), our findings can be explained assuming that in higher FFFS individuals the active avoidance behavior is manifested through the increased delta power necessary to inhibit painful sensory afferences that interfere with concentration necessary to rate pain sensation. This finding is interesting and needs of further replications.

According to Botvinick (2007), pain falls into a class of conflicting signals, as monetary loss and negative feedback, which are registered within the ACC and weighted as an aversive or costly event. This would have a direct impact on decision making, influencing subsequent adaptive behavioral adjustments in avoidance-learning mechanisms. As previously stated, we believe that in Hi-FFFS participants were mainly involved spontaneous defensive avoidance mechanisms to facilitate their cognitive control of painful experience (Deakin \& Graeff, 1991). In line with Botvinick (2007), Buzsáki (2006), Knyazev (2012), and Harmony (2013) suggestions, we think that in Hi-FFFS participants the relative increase in temporo-parietal delta activity taken together with the relative decrease in cortical gamma activity, across midfrontal, temporal, and parietal regions, can serve to activate active-avoidance control mechanisms in order to reduce focused attention on painful stimulation and to prevent negative outcome. These findings appear also in line with previous reports suggesting that a complex network, including sensory cortices, insula, hippocampus, amygdala, and periaqueductal gray, is activated to an incoming threat associated with painful stimulation (Corr \& McNaughton, 2012; Faull \& Pattinson, 2017; Mobbs et al., 2007).

It is important to underline that the present study has some limitations. First, the sample was restricted to right-handed women. Our findings thus may not be applicable to men or left-handed women. This is since it has been shown that right-handed females perceive a painful heat stimulus as more intense than do males (see, e.g., Paulson, Minoshima, Morrow, \& Casey, 1998) and this is associated with greater activation in the contralateral thalamus and anterior insula. In addition, pain threshold and tolerance in response to submerging a hand in very cold-water baths have been found higher on the right hand in dextral subjects (Pud, Golan, \& Pesta, 2009; Sarlani, Farooq, \& Greenspan, 2003; Schiff \& Gagliese, 1994). Second, this study was exploratory in nature since personality traits, as measured by the RST-PQ, have not yet been studied in relation to tonic $\mathrm{CP}$ and EEG oscillations. Third, participants rated subjective pain and distress intensity just at the end of the cold stimulation condition, and not continuously monitored during tonic $\mathrm{CP}$ stimulation. Thus, the results are tentative and need verification through additional research.

Acknowledgement. We want to give special thanks to the technician Emiliano Pes and all students participants and allowing us to conduct this study. This research was supported in part by a grant from La Sapienza University of Rome, Italy (project: C26A15RC5R) to Cecilia Guariglia (2015).

Author contributions. V.D.P. designed the methods and experiment. P.S. and B.P. performed data acquisition and signal processing. V.D.P. performed statistical analyses, interpreted the results, and wrote the paper. P.J.C. co-worked on results interpretation and suggested data analyses to test hypotheses derived from the Reinforcement Sensitivity Theory (RST). P.J.C. supervised discussion of the findings within a RST framework. All authors have contributed to, seen, and approved the manuscript.

Conflicts of interest. The authors have nothing to disclose. 


\section{References}

Amodio, D. M., Master, S. L., Yee, C. M., \& Taylor, S. E. (2008). Neurocognitive components of the behavioral inhibition and activation systems: Implications for theories of self-regulation. Psychophysiology, 45, 11-19. https://doi.org/10.1111/j.1469-8986.2007.00609.x.

Andersen, S. B., Moore, R. A., Venables, L., \& Corr, P. J. (2009). Electrophysiological correlates of anxious rumination. International Journal of Psychophysiology, 71, 156-169. https://doi.org/10.1016/j.ijpsycho.2008.09.004.

Apkarian, A. V., Bushnell, M. C., Treede, R.-D., \& Zubieta, J.-K. (2005). Human brain mechanisms of pain perception and regulation in health and disease. European Journal of Pain, 9, 463-484. https://doi.org/10. 1016/j.ejpain.2004.11.001.

Aron, A. R., Fletcher, P. C., Bullmore, E. T., Sahakian, B. J., \& Robbins, T. W. (2003). Stop-signal inhibition disrupted by damage to right inferior frontal gyrus in humans. Nature Neuroscience, 6, 115-116. https://doi.org/10.1038/nn1003.

Bartley, E. J., \& Fillingim, R. B. (2013). Sex differences in pain: A brief review of clinical and experimental findings. British Journal of Anaesthesia, 111, 52-58. https://doi.org/10.1093/bja/aet127.

Başar, E., Başar-Eroglu, C., Karakaş, S., \& Schürmann, M. (2001). Gamma, alpha, delta, and theta oscillations govern cognitive processes. International Journal of Psychophysiology, 39, 241-248. https://doi.org/10.1016/S01678760(00)00145-8.

Beaver, J. D., Lawrence, A. D., van Ditzhuijzen, J., Davis, M. H., Woods, A., \& Calder, A. J. (2006). Individual differences in reward drive predict neural responses to images of food. Journal of Neuroscience, 26, 5160-5166. https:// doi.org/10.1523/JNEUROSCI.0350-06.2006.

Benjamini, Y., \& Hochberg, Y. (1995). Controlling the false discovery rate: A practical and powerful approach to multiple testing. Journal of the Royal Statistical Society: Series B (Methodological), 57, 289-300. https://doi.org/ 10.1111/j.2517-6161.1995.tb02031.x.

Berkley, K. J. (1997). Sex differences in pain. Behavioral and Brain Sciences, 20, 371-380. https://doi.org/10.1017/S0140525X97221485.

Berridge, K. C. (1996). Food reward: Brain substrates of wanting and liking. Neuroscience \& Biobehavioral Reviews, 20, 1-25. https://doi.org/10.1016/ 0149-7634(95)00033-B.

Berridge, K. C., Robinson, T. E., \& Aldridge, J. W. (2009). Dissecting components of reward: 'Liking', 'wanting', and learning. Current Opinion in Pharmacology, 9, 65-73. https//doi.org/10.1016/j.coph.2008.12.014.

Bishop, S., Duncan, J., Brett, M., \& Lawrence, A. D. (2004). Prefrontal cortical function and anxiety: Controlling attention to threat-related stimuli. Nature Neuroscience, 7, 184-188. https://doi.org/10.1038/nn1173.

Botvinick, M. M. (2007). Conflict monitoring and decision making: Reconciling two perspectives on anterior cingulate function. Cognitive, Affective, \& Behavioral Neuroscience, 7, 356-366. https://sci-hub.tw/10. 3758/CABN.7.4.356.

Bush, G., Luu, P., \& Posner, M. I. (2000). Cognitive and emotional influences in anterior cingulate cortex. Trends in Cognitive Sciences, 4, 215-222. https:// doi.org/10.1016/S1364-6613(00)01483-2.

Buzsáki, G. (2006). Rhythms of the brain. Oxford: Oxford University Press.

Carver, C. S., \& White, T. L. (1994). Behavioral inhibition, behavioral activation, and affective responses to impending reward and punishment: The BIS/ BAS scales. Journal of Personality and Social Psychology, 67, 319-333. https:// doi.org/10.1037/0022-3514.67.2.319.

Castellanos, N. P., \& Makarov, V. A. (2006). Recovering EEG brain signals: Artifact suppression with wavelet enhanced independent component analysis. Journal of Neuroscience Methods, 158, 300-312. https://doi.org/10.1016/j. jneumeth.2006.05.033.

Cavanagh, J. F., \& Shackman, A. J. (2015). Frontal midline theta reflects anxiety and cognitive control: Meta-analytic evidence. Journal of PhysiologyParis, 109, 3-15. https://doi.org/10.1016/j.jphysparis.2014.04.003.

Chang, P.-F., Arendt-Nielsen, L., \& Chen, A. (2002a). Differential cerebral responses to aversive auditory arousal versus muscle pain: Specific EEG patterns are associated with human pain processing. Experimental Brain Research, 147, 387-393. https://doi.org/10.1007/s00221-002-1272-9.

Chang, P.-F., Arendt-Nielsen, L., \& Chen, A. (2002b). Dynamic changes and spatial correlation of EEG activities during cold pressor test in man. Brain Research Bulletin, 57, 667-675. https://doi.org/10.1016/S0361-9230(01)00763-8.
Chang, P.-F., Arendt-Nielsen, L., Graven-Nielsen, T., Svensson, P., \& Chen, A. (2004). Comparative EEG activation to skin pain and muscle pain induced by capsaicin injection. International Journal of Psychophysiology, 51, 117-126. https://doi.org/10.1016/j.ijpsycho.2003.01.001.

Chen, A. C., Chang, P.-F., \& Arendt-Nielsen, L. (2000). EEG and human pain: Topographic mapping of EEG power density in tonic cold pain using a universal cola glass cold bottle test. Neuroimage, 11, S734. https://doi.org/10. 1016/S1053-8119(00)91664-1.

Chen, A. C., Dworkin, S. F., Haug, J., \& Gehrig, J. (1989). Topographic brain measures of human pain and pain responsivity. Pain, 37, 129-141. https:// doi.org/10.1016/0304-3959(89)90125-5.

Chen, A. C., \& Rappelsberger, P. (1994). Brain and human pain: Topographic EEG amplitude and coherence mapping. Brain Topography, 7, 129-140. https://doi.org/10.1007/BF01186771.

Chen, A. C., Rappelsberger, P., \& Filz, O. (1998). Topology of EEG coherence changes may reflect differential neural network activation in cold and pain perception. Brain Topography, 11, 125-132. https://doi.org/10.1023/A: 1022254505510

Chi, S. E., Park, C. B., Lim, S. L., Park, E. H., Lee, Y. H., Lee, K. H., . . Kim, H. T. (2005). EEG and personality dimensions: A consideration based on the brain oscillatory systems. Personality and Individual Differences, 39, 669-681. https://doi.org/10.1016/j.paid.2005.02.017.

Coen, S. J., Kano, M., Farmer, A. D., Kumari, V., Giampietro, V., Brammer, M., ... Aziz, Q. (2011). Neuroticism influences brain activity during the experience of visceral pain. Gastroenterology, 141, 909-917. https://doi. org/10.1053/j.gastro.2011.06.008.

Cohen, M. X., Young, J., Baek, J.-M., Kessler, C., \& Ranganath, C. (2005). Individual differences in extraversion and dopamine genetics predict neural reward responses. Cognitive Brain Research, 25, 851-861. https//doi.org/10. 1016/j.cogbrainres.2005.09.018.

Corr, P. J. (2008). The reinforcement sensitivity theory of personality. Cambridge: Cambridge University Press.

Corr, P. J. (2016). Reinforcement sensitivity theory of personality questionnaires: Structural survey with recommendations. Personality and Individual Differences, 89, 60-64. https://doi.org/10.1016/j.paid.2015.09.045.

Corr, P. J., \& Cooper, A. J. (2016). The reinforcement sensitivity theory of personality questionnaire (RST-PQ): Development and validation. Psychological Assessment, 28, 1427-1440. https://doi.org/10.1037/pas0000273.

Corr, P. J., DeYoung, C. G., \& McNaughton, N. (2013). Motivation and personality: A neuropsychological perspective. Social and Personality Psychology Compass, 7, 158-175. https://doi.org/10.1111/spc3.12016.

Corr, P. J., \& McNaughton, N. (2012). Neuroscience and approach/avoidance personality traits: A two stage (valuation-motivation) approach. Neuroscience \& Biobehavioral Reviews, 36, 2339-2354. https://doi.org/10.1016/j.neubiorev. 2012.09.013.

Corsi, N., \& Colloca, L. (2017). Placebo and nocebo effects: The advantage of measuring expectations and psychological factors. Frontiers in Psychology, 8 , 308. https//doi.org/10.3389/fpsyg.2017.00308.

De Pascalis, V., Fracasso, F., \& Corr, P. (2017). Personality and Augmenting/ Reducing (A/R) in auditory event-related potentials (ERPs) during emotional visual stimulation. Scientific Reports, 7, 41588. https//doi.org/10.1038/srep41588.

De Pascalis, V., \& Scacchia, P. (2017a). The behavioural approach system and placebo analgesia during cold stimulation in women: A low-resolution brain electromagnetic tomography (LORETA) analysis of startle ERPs. Personality and Individual Differences, 118, 56-63. https//doi.org/10.1016/j.paid.2017.03.003.

De Pascalis, V., \& Scacchia, P. (2017b). Personality and placebo analgesia during cold stimulation in women: A Low-Resolution Brain Electromagnetic Tomography (LORETA) analysis of startle ERPs. Personality and Individual Differences, 118, 64-70. https//doi.org/10.1016/j.paid.2017.02.046.

De Pascalis, V., \& Scacchia, P. (2019). The influence of reward sensitivity, heart rate dynamics and EEG-delta activity on placebo analgesia. Behavioural Brain Research, 359, 320-332. https://doi.org/10.1016/j.bbr.2018.11.014.

De Pascalis, V., Varriale, V., \& D’Antuono, L. (2010). Event-related components of the punishment and reward sensitivity. Clinical Neurophysiology, 121, 60-76. https://doi.org/10.1016/j.clinph.2009.10.004.

Deakin, J. W., \& Graeff, F. G. (1991). 5-HT and mechanisms of defence. Journal of Psychopharmacology, 5, 305-315. https://doi.org/10.1177/ 026988119100500414. 
Delorme, A., Sejnowski, T., \& Makeig, S. (2007). Enhanced detection of artifacts in EEG data using higher-order statistics and independent component analysis. Neuroimage, 34, 1443-1449. https://doi.org/10.1016/j.neuroimage. 2006.11.004.

DeYoung, C. G. (2010). Personality neuroscience and the biology of traits. Social and Personality Psychology Compass, 4, 1165-1180. https//doi.org/ 10.1111/j.1751-9004.2010.00327.x.

Dowman, R., Rissacher, D., \& Schuckers, S. (2008). EEG indices of tonic painrelated activity in the somatosensory cortices. Clinical Neurophysiology, 119, 1201-1212. https://doi.org/10.1016/j.clinph.2008.01.019.

Drago, F., Caccamo, G., Continella, G., \& Scapagnini, U. (1984). Amphetamineinduced analgesia does not involve brain opioids. European Journal of Pharmacology, 101, 267-269. https//doi.org/10.1016/0014-2999(84)90168-7.

Efron, B., \& Efron, B. (1982). The jackknife, the bootstrap and other resampling plans (Vol. 38). Philadelphia, PA: SIAM.

Efron, B., \& Gong, G. (1983). A leisurely look at the bootstrap, the jackknife, and cross-validation. The American Statistician, 37, 36-48. https://doi.org/ 10.1080/00031305.1983.10483087.

Faull, O. K., \& Pattinson, K. T. (2017). The cortical connectivity of the periaqueductal gray and the conditioned response to the threat of breathlessness. Elife, 6, e21749. https://doi.org/10.7554/eLife.21749.

Ferracuti, S., Seri, S., Mattia, D., \& Cruccu, G. (1994). Quantitative EEG modifications during the cold water pressor test: Hemispheric and hand differences. International Journal of Psychophysiology, 17, 261-268. https://doi.org/10.1016/0167-8760(94)90068-X.

Gasser, T., Bächer, P., \& Möcks, J. (1982). Transformations towards the normal distribution of broad band spectral parameters of the EEG. Electroencephalography and Clinical Neurophysiology, 53, 119-124. https:// doi.org/10.1016/0013-4694(82)90112-2.

Giehl, J., Meyer-Brandis, G., Kunz, M., \& Lautenbacher, S. (2014). Responses to tonic heat pain in the ongoing EEG under conditions of controlled attention. Somatosensory \& Motor Research, 31, 40-48. https://doi.org/10.3109/ 08990220.2013 .837045 .

Gray, J. (1982). The neuropsychology of anxiety: An enquiry into the functions of the septo-hippocampal system. Oxford: Oxford University Press.

Gray, J. (1990). Brain systems that mediate both emotion and cognition. Cognition \& Emotion, 4, 269-288. https//doi.org/10.1080/02699939008410799.

Gray, J. A., \& McNaughton, N. (2000). The neuropsychology of anxiety: An enquiry into the functions of the septo-hippocampal system (2nd ed.). Oxford: Oxford University Press.

Gross, J., Schnitzler, A., Timmermann, L., \& Ploner, M. (2007). Gamma oscillations in human primary somatosensory cortex reflect pain perception. PLoS Biol, 5, e133. https://doi.org/10.1371/journal.pbio.0050133.

Güntekin, B., \& Başar, E. (2014). A review of brain oscillations in perception of faces and emotional pictures. Neuropsychologia, 58, 33-51. https://doi.org/ 10.1016/j.neuropsychologia.2014.03.014.

Harmon-Jones, E., Harmon-Jones, C., \& Price, T. F. (2013). What is approach motivation? Emotion Review, 5, 291-295. https://doi.org/10.1177/ 1754073913477509.

Harmony, T. (2013). The functional significance of delta oscillations in cognitive processing. Frontiers in Integrative Neuroscience, 7, 83. https://doi.org/ 10.3389/fnint.2013.00083.

Hauck, M., Lorenz, J., \& Engel, A. K. (2007). Attention to painful stimulation enhances $\gamma$-band activity and synchronization in human sensorimotor cortex. Journal of Neuroscience, 27, 9270-9277. https://doi.org/10.1523/ JNEUROSCI.2283-07.2007.

Huber, M. T., Bartling, J., Pachur, D., Woikowsky-Biedau, S., \& Lautenbacher, S. (2006). EEG responses to tonic heat pain. Experimental Brain Research, 173, 14-24. https://doi.org/10.1007/s00221-006-0366-1.

Jacobson, L., Javitt, D. C., \& Lavidor, M. (2011). Activation of inhibition: Diminishing impulsive behavior by direct current stimulation over the inferior frontal gyrus. Journal of Cognitive Neuroscience, 23, 3380-3387. https://doi.org/10.1162/jocn_a_00020.

Jensen, M. P., Karoly, P., \& Braver, S. (1986). The measurement of clinical pain intensity: A comparison of six methods. Pain, 27, 117-126. https://doi.org/ 10.1016/0304-3959(86)90228-9.

Kamarajan, C., Porjesz, B., Jones, K. A., Choi, K., Chorlian, D. B., Padmanabhapillai, A., ... Begleiter, H. (2004). The role of brain oscillations as functional correlates of cognitive systems: A study of frontal inhibitory control in alcoholism. International Journal of Psychophysiology, 51, 155-180. https://doi.org/10.1016/j.ijpsycho.2003.09.004.

Karjalainen, T., Tuominen, L., Manninen, S., Kalliokoski, K. K., Nuutila, P., Jääskeläinen, I. P., . . . Nummenmaa, L. (2016). Behavioural activation system sensitivity is associated with cerebral $\mu$-opioid receptor availability. Social Cognitive and Affective Neuroscience, 11, 1310-1316. https://doi.org/10.1093/ scan/nsw044.

Kelley, N. J., \& Schmeichel, B. J. (2016). Noninvasive stimulation over the dorsolateral prefrontal cortex facilitates the inhibition of motivated responding. Journal of Experimental Psychology: General, 145, 1702-1712. https://doi. org/10.1037/xge0000238.

Kennis, M., Rademaker, A. R., \& Geuze, E. (2013). Neural correlates of personality: An integrative review. Neuroscience \& Biobehavioral Reviews, 37, 73-95. https://doi.org/10.1016/j.neubiorev.2012.10.012.

Knyazev, G. (2006). EEG correlates of personality types. Netherlands Journal of Psychology, 62, 78-87. https://doi.org/10.1007/BF03061054.

Knyazev, G. (2007). Motivation, emotion, and their inhibitory control mirrored in brain oscillations. Neuroscience \& Biobehavioral Reviews, 31, 377-395. https://doi.org/10.1016/j.neubiorev.2006.10.004.

Knyazev, G. (2012). EEG delta oscillations as a correlate of basic homeostatic and motivational processes. Neuroscience \& Biobehavioral Reviews, 36, 677-695. https://doi.org/10.1016/j.neubiorev.2011.10.002.

Knyazev, G., \& Slobodskaya, H. (2003). Personality trait of behavioral inhibition is associated with oscillatory systems reciprocal relationships. International Journal of Psychophysiology, 48, 247-261. https://doi.org/10. 1016/S0167-8760(03)00072-2.

Knyazev, G., Slobodskoj-Plusnin, J., \& Bocharov, A. (2009). Event-related delta and theta synchronization during explicit and implicit emotion processing. Neuroscience, 164, 1588-1600. https://doi.org/10.1016/j. neuroscience.2009.09.057.

Koessler, L., Maillard, L., Benhadid, A., Vignal, J. P., Felblinger, J., Vespignani, H., \& Braun, M. (2009). Automated cortical projection of EEG sensors: Anatomical correlation via the international 10-10 system. Neuroimage, 46, 64-72. https://doi.org/10.1016/j.neuroimage.2009.02.006.

Kumari, V., Das, M., Wilson, G. D., Goswami, S., \& Sharma, T. (2007). Neuroticism and brain responses to anticipatory fear. Behavioral Neuroscience, 121, 643-652. https://doi.org/10.1037/0735-7044.121.4.643.

McNaughton, N., \& Corr, P. J. (2004). A two-dimensional neuropsychology of defense: Fear/anxiety and defensive distance. Neuroscience \& Biobehavioral Reviews, 28, 285-305. https://doi.org/10.1016/j.neubiorev.2004.03.005.

McNaughton, N., \& Corr, P. J. (2008). The neuropsychology of fear and anxiety: A foundation for reinforcement sensitivity theory. In P. J. Corr (Ed.), The reinforcement sensitivity theory of personality (pp. 44-94). Cambridge: Cambridge University Press.

Mobbs, D., Petrovic, P., Marchant, J. L., Hassabis, D., Weiskopf, N., Seymour, B., . . Frith, C. D. (2007). When fear is near: Threat imminence elicits prefrontal-periaqueductal gray shifts in humans. Science, 317, 1079-1083. https:// doi.org/10.1126/science.1144298.

Moore, R. A., Gale, A., Morris, P. H., \& Forrester, D. (2006). Theta phase locking across the neocortex reflects cortico-hippocampal recursive communication during goal conflict resolution. International Journal of Psychophysiology, 60, 260-273. https://doi.org/10.1016/j.ijpsycho.2005.06.003.

Moore, R. A., Mills, M., Marshman, P., \& Corr, P. J. (2012). Behavioural Inhibition System (BIS) sensitivity differentiates EEG theta responses during goal conflict in a continuous monitoring task. International Journal of Psychophysiology, 85, 135-144. https://doi.org/10.1016/j.ijpsycho.2012.06.006.

Neal, L. B., \& Gable, P. A. (2016). Neurophysiological markers of multiple facets of impulsivity. Biological Psychology, 115, 64-68. https://doi.org/10.1016/ j.biopsycho.2016.01.006.

Neal, L. B., \& Gable, P. A. (2017). Regulatory control and impulsivity relate to resting frontal activity. Social Cognitive and Affective Neuroscience, 12, 1377-1383. https://doi.org/10.1093/scan/nsx080.

Neo, P. S. H., \& McNaughton, N. (2011). Frontal theta power linked to neuroticism and avoidance. Cognitive, Affective, \& Behavioral Neuroscience, 11, 396-403. https://doi.org/10.3758/s13415-011-0038-x.

Nir, R.-R., Sinai, A., Moont, R., Harari, E., \& Yarnitsky, D. (2012). Tonic pain and continuous EEG: Prediction of subjective pain perception by alpha-1 
power during stimulation and at rest. Clinical Neurophysiology, 123, 605-612. https://doi.org/10.1016/j.clinph.2011.08.006.

Okamoto, M., Dan, H., Sakamoto, K., Takeo, K., Shimizu, K., Kohno, S., . . . Kohyama, K. (2004). Three-dimensional probabilistic anatomical craniocerebral correlation via the international 10-20 system oriented for transcranial functional brain mapping. Neuroimage, 21, 99-111. https://doi.org/10. 1016/j.neuroimage.2003.08.026.

Olbrich, S., Jödicke, J., Sander, C., Himmerich, H., \& Hegerl, U. (2011). ICAbased muscle artefact correction of EEG data: What is muscle and what is brain? Comment on McMenamin et al. Neuroimage, 54, 1-3. https://doi. org/10.1016/j.neuroimage.2010.04.256.

Oldfield, R. C. (1971). The assessment and analysis of handedness: The Edinburgh inventory. Neuropsychologia, 9, 97-113. https://doi.org/10. 1016/0028-3932(71)90067-4.

Paulson, P. E., Minoshima, S., Morrow, T. J., \& Casey, K. L. (1998). Gender differences in pain perception and patterns of cerebral activation during noxious heat stimulation in humans. Pain, 76, 223-229. https://doi.org/10.1016/ S0304-3959(98)00048-7.

Peciña, M., Azhar, H., Love, T. M., Lu, T., Fredrickson, B. L., Stohler, C. S., \& Zubieta, J.-K. (2013). Personality trait predictors of placebo analgesia and neurobiological correlates. Neuropsychopharmacology, 38, 639-646. https://doi.org/10.1038/npp.2012.227.

Peciña, S., \& Berridge, K. (2000). Opioid site in nucleus accumbens shell mediates eating and hedonic 'liking' for food: Map based on microinjection Fos plumes. Brain Research, 863, 71-86. https://doi.org/10.1016/S0006-8993(00) 02102-8.

Peng, W., Hu, L., Zhang, Z., \& Hu, Y. (2014). Changes of spontaneous oscillatory activity to tonic heat pain. PLoS One, 9, e91052. https://doi.org/10. 1371/journal.pone.0091052.

Perkins, A., Kemp, S., \& Corr, P. (2007). Fear and anxiety as separable emotions: An investigation of the revised reinforcement sensitivity theory of personality. Emotion, 7, 252-261. https://doi.org/10.1037/1528-3542.7.2.252.

Pizzagalli, D. A., Oakes, T. R., \& Davidson, R. J. (2003). Coupling of theta activity and glucose metabolism in the human rostral anterior cingulate cortex: An EEG/PET study of normal and depressed subjects. Psychophysiology, 40, 939-949. https://doi.org/10.1111/1469-8986.00112.

Ploner, M., Sorg, C., \& Gross, J. (2017). Brain rhythms of pain. Trends in Cognitive Sciences, 21, 100-110. https://doi.org/10.1016/j.tics.2016.12.001.

Pud, D., Golan, Y., \& Pesta, R. (2009). Hand dominancy-A feature affecting sensitivity to pain. Neuroscience Letters, 467, 237-240. https://doi.org/10. 1016/j.neulet.2009.10.048.

Putman, P. (2011). Resting state EEG delta-beta coherence in relation to anxiety, behavioral inhibition, and selective attentional processing of threatening stimuli. International Journal of Psychophysiology, 80, 63-68. https://doi.org/ 10.1016/j.ijpsycho.2011.01.011.

Russ, M. J., Campbell, S. S., Kakuma, T., Harrison, K., \& Zanine, E. (1999). EEG theta activity and pain insensitivity in self-injurious borderline patients. Psychiatry Research, 89, 201-214. https://doi.org/10.1016/S0165-1781(99) 00113-4.

Sarlani, E., Farooq, N., \& Greenspan, J. D. (2003). Gender and laterality differences in thermosensation throughout the perceptible range. Pain, 106, 9-18. https://doi.org/10.1016/S0304-3959(03)00211-2.

Schiff, B., \& Gagliese, L. (1994). The consequences of experimentally induced and chronic unilateral pain: Reflections of hemispheric lateralization of emotion. Cortex, 30, 255-267. https://doi.org/10.1016/S0010-9452(13)80197-9.

Schulz, E., May, E. S., Postorino, M., Tiemann, L., Nickel, M. M., Witkovsky, V., ... Ploner, M. (2015). Prefrontal gamma oscillations encode tonic pain in humans. Cerebral Cortex, 25, 4407-4414. https://doi.org/10.1093/cercor/ bhv043.

Schürmann, M., Başar-Eroglu, C., Kolev, V., \& Başar, E. (2001). Delta responses and cognitive processing: Single-trial evaluations of human visual
P300. International Journal of Psychophysiology, 39, 229-239. https://doi.org/ 10.1016/S0167-8760(00)00144-6.

Schweinhardt, P., Seminowicz, D. A., Jaeger, E., Duncan, G. H., \& Bushnell, M. C. (2009). The anatomy of the mesolimbic reward system: A link between personality and the placebo analgesic response. Journal of Neuroscience, 29, 4882-4887. https://doi.org/10.1523/JNEUROSCI.5634-08.2009.

Scott, D. J., Stohler, C. S., Egnatuk, C. M., Wang, H., Koeppe, R. A., \& Zubieta, J.-K. (2007). Individual differences in reward responding explain placebo-induced expectations and effects. Neuron, 55, 325-336. https:// doi.org/10.1016/j.neuron.2007.06.028.

Scott, D. J., Stohler, C. S., Egnatuk, C. M., Wang, H., Koeppe, R. A., \& Zubieta, J.-K. (2008). Placebo and nocebo effects are defined by opposite opioid and dopaminergic responses. Archives of General Psychiatry, 65, 220-231. https://doi.org/10.1001/archgenpsychiatry.2007.34.

Shao, S., Shen, K., Yu, K., Wilder-Smith, E. P., \& Li, X. (2012). Frequencydomain EEG source analysis for acute tonic cold pain perception. Clinical Neurophysiology, 123, 2042-2049. https://doi.org/10.1016/j.clinph.2012.02. 084.

Shimizu, T., Iwata, S.-i., Morioka, H., Masuyama, T., Fukuda, T., \& Nomoto, M. (2004). Antinociceptive mechanism of 1-DOPA. Pain, 110, 246-249. https://doi.org/10.1016/j.pain.2004.03.038.

Shoaib, M., Spanagel, R., Stohr, T., \& Shippenberg, T. (1995). Strain differences in the rewarding and dopamine-releasing effects of morphine in rats. Psychopharmacology, 117, 240-247. https://doi.org/10.1007/ BF02245193.

Spielberger, C. D., Gorsuch, R., Lushene, R., Vagg, P. R., \& Jacobs, G. A. (1988). Manual for the state trait anxiety inventory (form Y). Palo Alto, CA: Consulting Psychologist Press.

Stramaccia, D. F., Penolazzi, B., Sartori, G., Braga, M., Mondini, S., \& Galfano, G. (2015). Assessing the effects of tDCS over a delayed response inhibition task by targeting the right inferior frontal gyrus and right dorsolateral prefrontal cortex. Experimental Brain Research, 233, 2283-2290. https://doi.org/10.1007/s00221-015-4297-6.

Streff, A., Kuehl, L. K., Michaux, G., \& Anton, F. (2010). Differential physiological effects during tonic painful hand immersion tests using hot and ice water. European Journal of Pain, 14, 266-272. https://doi.org/10.1016/j. ejpain.2009.05.011.

Tiemann, L., Schulz, E., Gross, J., \& Ploner, M. (2010). Gamma oscillations as a neuronal correlate of the attentional effects of pain. Pain, 150, 302-308. https://doi.org/10.1016/j.pain.2010.05.014.

Veerasarn, P., \& Stohler, C. S. (1992). The effect of experimental muscle pain on the background electrical brain activity. Pain, 49, 349-360. https://doi. org/10.1016/0304-3959(92)90242-4.

Wacker, J., Chavanon, M.-L., \& Stemmler, G. (2010). Resting EEG signatures of agentic extraversion: New results and meta-analytic integration. Journal of Research in Personality, 44, 167-179. https://doi.org/10.1016/j.jrp.2009. 12.004.

Wyvell, C. L., \& Berridge, K. C. (2000). Intra-accumbens amphetamine increases the conditioned incentive salience of sucrose reward: Enhancement of reward "wanting" without enhanced "liking" or response reinforcement. Journal of Neuroscience, 20, 8122-8130. https://doi.org/10. 1523/JNEUROSCI.20-21-08122.2000.

Yacubian, J., Sommer, T., Schroeder, K., Gläscher, J., Braus, D. F., \& Büchel, C. (2007). Subregions of the ventral striatum show preferential coding of reward magnitude and probability. NeuroImage, 38, 557-563. https://doi. org/10.1016/j.neuroimage.2007.08.007.

Zubieta, J.-K., Bueller, J. A., Jackson, L. R., Scott, D. J., Xu, Y., Koeppe, R. A., . . Stohler, C. S. (2005). Placebo effects mediated by endogenous opioid activity on $\mu$-opioid receptors. Journal of Neuroscience, 25, 7754-7762. https://doi.org/10. 1523/JNEUROSCI.0439-05.2005. 